\title{
An Average Body Circumference Can Be a Substitute for Body Mass Index in Women
}

\author{
Antonis Polymeris, Peter D. Papapetrou, and Georgios Katsoulis \\ Second Division of Endocrinology, Alexandra Hospital, 11528 Athens, Greece \\ Correspondence should be addressed to Antonis Polymeris; antonispolymeris@gmail.com
}

Received 30 July 2014; Accepted 6 November 2014; Published 20 November 2014

Academic Editor: Karen J. Coleman

Copyright ( 2014 Antonis Polymeris et al. This is an open access article distributed under the Creative Commons Attribution License, which permits unrestricted use, distribution, and reproduction in any medium, provided the original work is properly cited.

\begin{abstract}
Introduction. Significant correlations between BMI and some body circumferences have been previously reported. In this study we investigated if the average of the sum of eight body circumferences can be a substitute for BMI. Patients and Methods. BMI and eight body circumferences (neck, waist, hip, arm, forearm, wrist, thigh, and ankle) were measured in 193 apparently healthy women aged 20-83, and within a wide range of BMI. Women with BMI $\leq 24.9$ were designated as normal, with BMI 25-29.9 as overweight and with $\mathrm{BMI} \geq 30$ as obese. The relationship of the average body circumference $(\mathrm{ABC})$ of the sum of the eight circumferences, and of each individual circumference with BMI, was evaluated. Results. ABC had the strongest correlation with BMI $(r=0.95$, $P<0.001)$ among all the circumferences tested. Hip circumference had the strongest correlation with BMI $(r=0.89, P<0.001)$ among the circumferences of individual body sites. Receiver-Operator Characteristic analysis showed that women with $\mathrm{ABC}>$ $44.0 \mathrm{~cm}$ could be recognized as having BMI $\geq 25$ with sensitivity $90.2 \%$ and specificity $88.5 \%$, while women with $\mathrm{ABC}>47.1 \mathrm{~cm}$ could be diagnosed as having BMI $\geq 30$ with sensitivity $92.2 \%$ and specificity $91.5 \%$. Conclusion. An average body circumference strongly correlated with BMI in women and can serve as a surrogate of BMI.
\end{abstract}

\section{Introduction}

Body mass index (BMI) has been used extensively as a convenient and inexpensive measure of obesity in epidemiological studies since its introduction in 1972 [1]. In a considerable number of studies, high BMI has been associated with increased cardiovascular morbidity and mortality, resistance to insulin, and diabetes mellitus [2]. However, while BMI is appropriate for population studies, it should not be used as an index of obesity in individual patients [1], but this is a standard practice by many clinicians and is recommended by health authorities as a screening test for obesity [3-5]. A major shortcoming of BMI is that it does not give any estimation of the distribution of fat in the human body. Moreover, for the estimation of BMI, special equipment for the measurement of body weight and height is needed. BenNoun et al. [6] found a significant correlation between neck circumference and BMI and proposed that neck circumference could be used to identify BMI-defined overweight or obese patients. In the present work, we investigated the relationship between BMI and several body circumferences in women and we found that the best predictor of BMI among various body circumferences is the average of the sum of eight individual body circumferences $(A B C)$.

\section{Participants and Methods}

The study population included 193 apparently healthy women aged 20-83 (60.0 \pm 13.6 , mean $\pm S D)$. This population consisted of some women from the hospital personnel and some of their relatives, as well as some women who referred to the endocrine clinic of the hospital for evaluation of their thyroid function, and some of their healthy relatives. Only euthyroid women without significant goiter and those with microscopic thyroid nodules not affecting the neck circumference were included. Diabetic patients and women with somatic deformities were excluded. The participant women were categorized in three subgroups as shown in Table 1: those with BMI $\leq 24.9$ designated as "normal," with 
TABLE 1: Anthropometric parameters of the study population.

\begin{tabular}{|c|c|c|c|c|}
\hline Participants & $\begin{array}{c}\text { All } \\
(n=193)\end{array}$ & $\begin{array}{l}\text { Normal } \\
(n=61)\end{array}$ & $\begin{array}{l}\text { Overweight } \\
(n=68)\end{array}$ & $\begin{array}{c}\text { Obese } \\
(n=64)\end{array}$ \\
\hline \multicolumn{5}{|l|}{ Parameter } \\
\hline Age & $\begin{array}{c}48.9 \\
(46.8-51.0)\end{array}$ & $\begin{array}{c}44.5 \\
(41.2-48.1)\end{array}$ & $\begin{array}{c}52.9 \\
(49.8-56.1)\end{array}$ & $\begin{array}{c}49.1 \\
(45.0-53.7)\end{array}$ \\
\hline Weight (kg) & $\begin{array}{c}71.1 \\
(69.2-73.1)\end{array}$ & $\begin{array}{c}58.3 \\
(56.9-59.7)\end{array}$ & $\begin{array}{c}69.5 \\
(67.9-71.0)\end{array}$ & $\begin{array}{c}88.1 \\
(85.3-91.1)\end{array}$ \\
\hline Height $(\mathrm{cm})$ & $\begin{array}{c}160.0 \\
(159.2-160.8)\end{array}$ & $\begin{array}{c}161.4 \\
(160.1-162.6)\end{array}$ & $\begin{array}{c}159.1 \\
(157.8-160.4)\end{array}$ & $\begin{array}{c}159.7 \\
(157.9-161.5)\end{array}$ \\
\hline BMI & $\begin{array}{c}27.8 \\
(27.0-28.6)\end{array}$ & $\begin{array}{c}22.4 \\
(21.9-22.9)\end{array}$ & $\begin{array}{c}27.5 \\
(27.1-27.8)\end{array}$ & $\begin{array}{c}34.6 \\
(33.7-35.5)\end{array}$ \\
\hline \multicolumn{5}{|l|}{ Circumference of $(\mathrm{cm})$} \\
\hline Neck & $\begin{array}{c}33.8 \\
(33.5-34.1)\end{array}$ & $\begin{array}{c}31.9 \\
(31.5-32.2)\end{array}$ & $\begin{array}{c}33.6 \\
(33.3-34.0)\end{array}$ & $\begin{array}{c}35.9 \\
(35.4-36.5)\end{array}$ \\
\hline Waist & $\begin{array}{c}91.1 \\
(89.3-92.9)\end{array}$ & $\begin{array}{c}79.8 \\
(78.0-81.7)\end{array}$ & $\begin{array}{c}89.6 \\
(87.9-91.4)\end{array}$ & $\begin{array}{c}105.0 \\
(102.4-107.6)\end{array}$ \\
\hline Hip & $\begin{array}{c}107.1 \\
(105.6-108.6)\end{array}$ & $\begin{array}{c}97.8 \\
(96.7-98.9)\end{array}$ & $\begin{array}{c}105.0 \\
(103.8-106.3)\end{array}$ & $\begin{array}{c}119.2 \\
(116.8-121.6)\end{array}$ \\
\hline Arm & $\begin{array}{c}26.5 \\
(26.1-27.0)\end{array}$ & $\begin{array}{c}23.8 \\
(23.5-24.2)\end{array}$ & $\begin{array}{c}26.5 \\
(26.1-26.9)\end{array}$ & $\begin{array}{c}29.4 \\
(28.7-30.2)\end{array}$ \\
\hline Forearm & $\begin{array}{c}24.90 \\
(24.6-25.2)\end{array}$ & $\begin{array}{c}23.1 \\
(22.8-23.5)\end{array}$ & $\begin{array}{c}24.8 \\
(24.5-25.1)\end{array}$ & $\begin{array}{c}26.8 \\
(26.3-27.5)\end{array}$ \\
\hline Wrist & $\begin{array}{c}16.0 \\
(15.8-16.2)\end{array}$ & $\begin{array}{c}15.1 \\
(14.9-15.4)\end{array}$ & $\begin{array}{c}15.9 \\
(15.7-16.2)\end{array}$ & $\begin{array}{c}16.9 \\
(16.5-17.2)\end{array}$ \\
\hline Thigh & $\begin{array}{c}45.3 \\
(44.6-46.1)\end{array}$ & $\begin{array}{c}41.5 \\
(40.6-42.4)\end{array}$ & $\begin{array}{c}44.4 \\
(43.6-45.3)\end{array}$ & $\begin{array}{c}50.4 \\
(49.2-51.7)\end{array}$ \\
\hline Ankle & $\begin{array}{c}23.2 \\
(22.9-23.5)\end{array}$ & $\begin{array}{c}21.8 \\
(21.4-22.2)\end{array}$ & $\begin{array}{c}23.1 \\
(22.7-23.5)\end{array}$ & $\begin{array}{c}24.8 \\
(24.3-25.4)\end{array}$ \\
\hline Waist/hip ratio & $\begin{array}{c}0.85 \\
(0.84-0.86)\end{array}$ & $\begin{array}{c}0.82 \\
(0.80-0.83)\end{array}$ & $\begin{array}{c}0.85 \\
(0.84-0.87)\end{array}$ & $\begin{array}{c}0.88 \\
(0.86-0.90)\end{array}$ \\
\hline \multicolumn{5}{|l|}{ Mean circumference of $(\mathrm{cm})$} \\
\hline $\mathrm{ABC}^{\mathrm{a}}$ & $\begin{array}{c}46.1 \\
(45.5-46.7)\end{array}$ & $\begin{array}{c}41.9 \\
(41.5-42.4)\end{array}$ & $\begin{array}{c}45.4 \\
(45.0-45.9)\end{array}$ & $\begin{array}{c}51.2 \\
(50.4-52.0)\end{array}$ \\
\hline $\mathrm{UBC}^{\mathrm{b}}$ & $\begin{array}{c}38.5 \\
(38.0-39.1)\end{array}$ & $\begin{array}{c}34.8 \\
(34.3-35.3)\end{array}$ & $\begin{array}{c}38.1 \\
(37.7-38.6)\end{array}$ & $\begin{array}{c}42.9 \\
(42.1-43.6)\end{array}$ \\
\hline $\mathrm{LBC}^{\mathrm{c}}$ & $\begin{array}{c}58.6 \\
(57.8-59.4)\end{array}$ & $\begin{array}{c}53.8 \\
(53.2-54.4)\end{array}$ & $\begin{array}{c}57.6 \\
(56.9-58.2)\end{array}$ & $\begin{array}{c}64.9 \\
(63.7-66.1)\end{array}$ \\
\hline$(\mathrm{N}+\mathrm{W}+\mathrm{H}+\mathrm{A}+\mathrm{Th}) / 5$ & $\begin{array}{c}60.9 \\
(60.0-61.7)\end{array}$ & $\begin{array}{c}55.0 \\
(54.4-55.7)\end{array}$ & $\begin{array}{c}59.9 \\
(59.3-60.5)\end{array}$ & $\begin{array}{c}68.1 \\
(67.0-69.2)\end{array}$ \\
\hline$($ Waist + hip + arm + thigh $) / 4$ & $\begin{array}{c}68.3 \\
(67.1-69.6)\end{array}$ & $\begin{array}{c}60.8 \\
(60.1-61.6)\end{array}$ & $\begin{array}{c}66.5 \\
(65.8-67.2)\end{array}$ & $\begin{array}{c}76.1 \\
(74.8-77.5)\end{array}$ \\
\hline$($ Neck + waist + hip $) / 3$ & $\begin{array}{c}77.4 \\
(76.3-78.6)\end{array}$ & $\begin{array}{c}69.9 \\
(69.0-70.8)\end{array}$ & $\begin{array}{c}76.2 \\
(75.4-77.0)\end{array}$ & $\begin{array}{c}86.8 \\
(85.3-88.3)\end{array}$ \\
\hline (Waist + hip)/2 & $\begin{array}{c}99.2 \\
(97.6-100.8)\end{array}$ & $\begin{array}{c}88.9 \\
(87.6-90.2)\end{array}$ & $\begin{array}{c}97.4 \\
(96.3-98.6)\end{array}$ & $\begin{array}{c}112.2 \\
(110.2-114.3)\end{array}$ \\
\hline
\end{tabular}

Normal = women with BMI $\leq 24.9$. Overweight $=$ women with BMI 25-29.9. Obese $=$ women with BMI $\geq 30$.

${ }^{a} A B C$, average body circumference, average of (neck + waist + hip + arm + forearm + wrist + thigh + ankle).

${ }^{b} \mathrm{UBC}$, upper body circumference, average of (neck + waist + arm + forearm + wrist).

${ }^{c} \mathrm{LBC}$, lower body circumference, average of (hip + thigh + ankle).

$\mathrm{N}=$ neck, $\mathrm{W}=$ waist, $\mathrm{H}=$ hip, $\mathrm{A}=$ arm, $\mathrm{F}=$ forearm, $\mathrm{Wr}=$ wrist, $\mathrm{Th}=$ thigh, and $\mathrm{Ank}=$ ankle. Geometric means $(95 \% \mathrm{CI})$ are presented. 
BMI 25-29.9 (overweight), and with BMI $\geq 30$ (obese). The study was approved by the Scientific Committee of the Alexandra Hospital and the data were collected with the participant's informed consent.

Body weight and height were measured with standard techniques in the women wearing light indoor clothing. Body weight was recorded to the nearest $0.1 \mathrm{~kg}$ and height to the nearest $0.5 \mathrm{~cm}$. BMI was calculated as weight in $\mathrm{kg}$ divided by the square of height in meters. Body circumferences were measured using a flexible cloth tape measure. The measurement of the body circumferences was performed with the individual standing and looking straight ahead, with her legs in loose contact and her arms hanging close to her body. The neck circumference was measured just above the cricoid cartilage, the waist circumference at the middle of the distance between the lower rib and the iliac crest, the hip circumference around the widest portion of the buttocks, the distal thigh circumference ten centimeters above the upper edge of the patella, the ankle circumference at the narrowest point of the region, the arm circumference at the middle of the distance between the acromion and olecranon process, the circumference of the forearm at the widest portion of the forearm, and the wrist circumference around the bony part of the wrist.

Eight individual body circumferences were measured and the averages of several different sums of individual body circumferences were also calculated. Average body circumference $(A B C)$ is the average of the sum of the eight circumferences (neck, waist, hip, arm, forearm, wrist, thigh, and ankle). Upper body circumference (UBC) is the average of the sum of neck, waist, arm, forearm, and wrist. Lower body circumference (LBC) is the average of the sum of hip, thigh, and ankle.

\section{Statistical Analysis}

A Kolmogorov-Smirnov normality test showed that some of the parameters depicted in Table 1 had nonnormal distribution and therefore the geometric means and 95\% CI (confidence interval) are presented. Because of nonnormality of the variables, simple Spearman Rank correlations were performed between each circumference and BMI. A ReceiverOperator Characteristic (ROC) analysis was performed in order to evaluate the diagnostic ability of body circumferences to recognize persons within certain ranges of BMI. The statistical analysis was performed using GraphPad Prism Software, San Diego, CA, USA.

\section{Results}

Anthropometric characteristics and the geometric means (95\% CI) of some parameters for the entire study population and for three BMI stratified subpopulations are shown in Table 1.

4.1. Relationship between BMI and Individual Body Circumferences. Hip circumference showed the strongest simple correlation with BMI among the circumferences of individual
TABLE 2: Spearman Rank correlations of BMI with body circumferences.

\begin{tabular}{|c|c|c|c|c|}
\hline \multirow[t]{2}{*}{ Participants } & $\begin{array}{c}\text { All } \\
(n=193)\end{array}$ & $\begin{array}{l}\text { Normal } \\
(n=61)\end{array}$ & $\begin{array}{l}\text { Overweight } \\
(n=68)\end{array}$ & $\begin{array}{c}\text { Obese } \\
(n=64)\end{array}$ \\
\hline & $R$ & $R$ & $R$ & $R$ \\
\hline \multicolumn{5}{|l|}{$\begin{array}{l}\text { BMI with } \\
\text { circumference of }\end{array}$} \\
\hline Hip & 0.89 & 0.56 & 0.53 & 0.61 \\
\hline Waist & 0.84 & 0.49 & 0.57 & 0.56 \\
\hline Arm & 0.82 & 0.42 & 0.47 & 0.49 \\
\hline Forearm & 0.79 & 0.52 & 0.42 & 0.57 \\
\hline Neck & 0.77 & 0.48 & 0.32 & 0.54 \\
\hline Thigh & 0.73 & 0.45 & 0.31 & 0.50 \\
\hline Wrist & 0.61 & $0.30^{* *}$ & 0.29 & 0.38 \\
\hline Ankle & 0.61 & 0.39 & $0.22^{*}$ & 0.44 \\
\hline Waist/hip ratio & 0.40 & $0.08^{*}$ & $0.28^{* *}$ & $0.10^{*}$ \\
\hline $\mathrm{ABC}^{\mathrm{a}}$ & 0.95 & 0.60 & 0.77 & 0.80 \\
\hline $\mathrm{UBC}^{\mathrm{b}}$ & 0.91 & 0.54 & 0.69 & 0.67 \\
\hline $\mathrm{LBC}^{\mathrm{c}}$ & 0.89 & 0.49 & 0.49 & 0.65 \\
\hline $\begin{array}{l}(\mathrm{N}+\mathrm{W}+\mathrm{H}+\mathrm{A} \\
+\mathrm{Th}) / 5\end{array}$ & 0.95 & 0.58 & 0.77 & 0.78 \\
\hline $\begin{array}{l}(\mathrm{W}+\mathrm{H}+\mathrm{A}+ \\
\mathrm{Th}) / 4\end{array}$ & 0.94 & 0.57 & 0.75 & 0.77 \\
\hline $\begin{array}{l}\text { (Neck + waist + } \\
\text { hip)/3 }\end{array}$ & 0.93 & 0.55 & 0.72 & 0.73 \\
\hline (Waist + hip)/2 & 0.92 & 0.54 & 0.70 & 0.71 \\
\hline
\end{tabular}

Normal, with BMI $\leq 24.9$. Overweight, with BMI 25-29.9. Obese, with BMI $\geq 30$.

${ }^{\mathrm{a}} \mathrm{ABC}=$ average body circumference, average of (neck + waist + hip + arm + forearm + wrist + thigh + ankle).

${ }^{b} \mathrm{UBC}$, upper body circumference, average of (neck + waist + arm + forearm + wrist).

${ }^{c}$ LBC, lower body circumference, average of (hip + thigh + Ankle). $N=$ neck, $\mathrm{W}=$ waist, $\mathrm{H}=\mathrm{Hip}, \mathrm{A}=\mathrm{arm}$, and $\mathrm{Th}=$ thigh .

The coefficients $(R)$ marked with one asterisk were nonsignificant, with two asterisks having $P=0.02$, and the rest without asterisk had $P \leq 0.001$.

body sites $(r=0.89, P<0.001)$. Average values of various sums of body circumferences showed generally stronger simple correlations with BMI when compared with circumferences of individual body sites; thus, the $\mathrm{ABC}$ had the strongest correlation with BMI among all the circumferences tested $(r=0.95, P<0.001)$ (Table 2$)$.

4.2. Relationship of $B M I$ with $A B C, U B C$, and $L B C$. The $\log$ transformed values of the $\mathrm{BMI}$ and $\mathrm{ABC}$ values in the entire study population showed normal distribution. Simple linear regression of $\log \mathrm{BMI}$ on $\log \mathrm{ABC}$ showed a strong correlation between these two parameters in the entire study population $(r=0.94, P<0.001)$; the regression coefficient $r^{2}=0.89$ implies that $89 \%$ of the variation of BMI may be explained by $\mathrm{ABC}$ (Figure 1). In order to adjust for age, $\log \mathrm{BMI}$ was regressed simultaneously on $\log \mathrm{ABC}$ and age whose distribution was not far from normal. Age did not significantly affect the effect of $\mathrm{ABC}$ on BMI (beta coefficient for $\mathrm{ABC}$ 0.93, and for age -0.09). Simple correlation of BMI 
TABLE 3: Spearman Rank intercorrelations between BMI, body weight, height, and average body circumference (ABC).

\begin{tabular}{|c|c|c|c|c|}
\hline \multirow[t]{2}{*}{ Participants } & $\begin{array}{c}\text { All } \\
(n=193)\end{array}$ & $\begin{array}{l}\text { Normal } \\
(n=61)\end{array}$ & $\begin{array}{c}\text { Overweight } \\
(n=68)\end{array}$ & $\begin{array}{c}\text { Obese } \\
(n=64)\end{array}$ \\
\hline & R & R & $R$ & $R$ \\
\hline \multicolumn{5}{|l|}{ Correlation of } \\
\hline \multicolumn{5}{|l|}{ BMI with } \\
\hline Body weight & 0.93 & 0.73 & 0.69 & 0.69 \\
\hline Height & $-0.12^{*}$ & $-0.11^{*}$ & $0.16^{*}$ & $-0.08^{*}$ \\
\hline $\mathrm{ABC}^{\mathrm{a}}$ & 0.95 & 0.60 & 0.77 & 0.80 \\
\hline \multicolumn{5}{|c|}{ Body weight with } \\
\hline Height & 0.22 & 0.56 & 0.80 & 0.63 \\
\hline $\mathrm{ABC}^{\mathrm{a}}$ & 0.94 & 0.63 & 0.76 & 0.82 \\
\hline \multicolumn{5}{|l|}{$\mathrm{ABC}^{\mathrm{a}}$ with } \\
\hline Height & $0.03^{*}$ & $0.19^{*}$ & 0.40 & $0.29^{* *}$ \\
\hline
\end{tabular}

Normal, with BMI $\leq 24.9$, overweight, with BMI 25-29.9, and obese, with $\mathrm{BMI} \geq 30$.

${ }^{\mathrm{a}} \mathrm{ABC}$, average body circumference, average of (neck + waist + hip + arm + forearm + wrist + thigh + ankle).

The coefficients $(R)$ with one asterisk were not significant, with two asterisks having $P=0.03$, and the rest without asterisk had $P<0.001$.

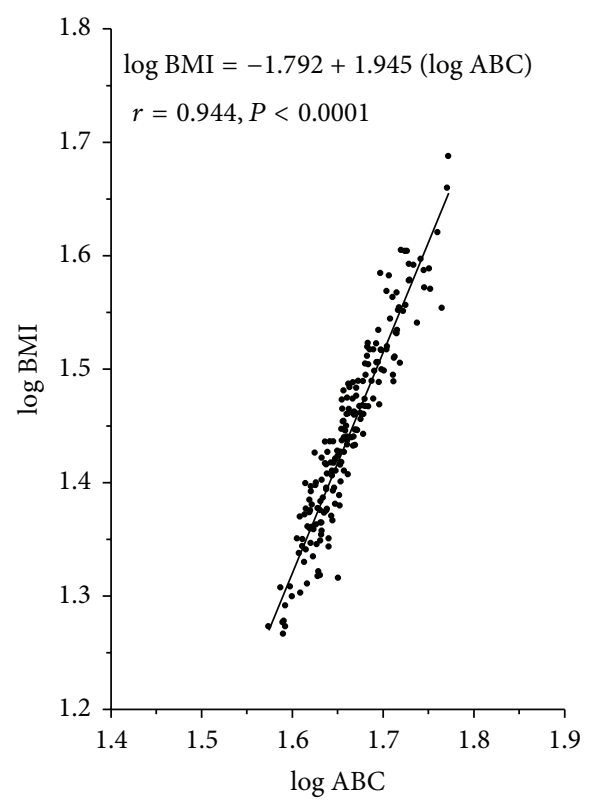

Figure 1: Linear regression of log ABC (average body circumference) on $\log \mathrm{BMI}$ in the entire study population.

with $\mathrm{ABC}(r=0.95)$ was slightly higher when compared with that between BMI and UBC $(r=0.91)$ or that between BMI and LBC $(r=0.89)$ (Table 2). A similar trend was observed more or less in the three subgroups.

In the entire study population, $\mathrm{ABC}$ was highly correlated with body weight $(r=0.94, P<0.001)$ but not with height (Table 3). A strong simple correlation was also found between $\mathrm{ABC}$ and body weight but not with height in all the subgroups, except in the overweight women in whom $A B C$

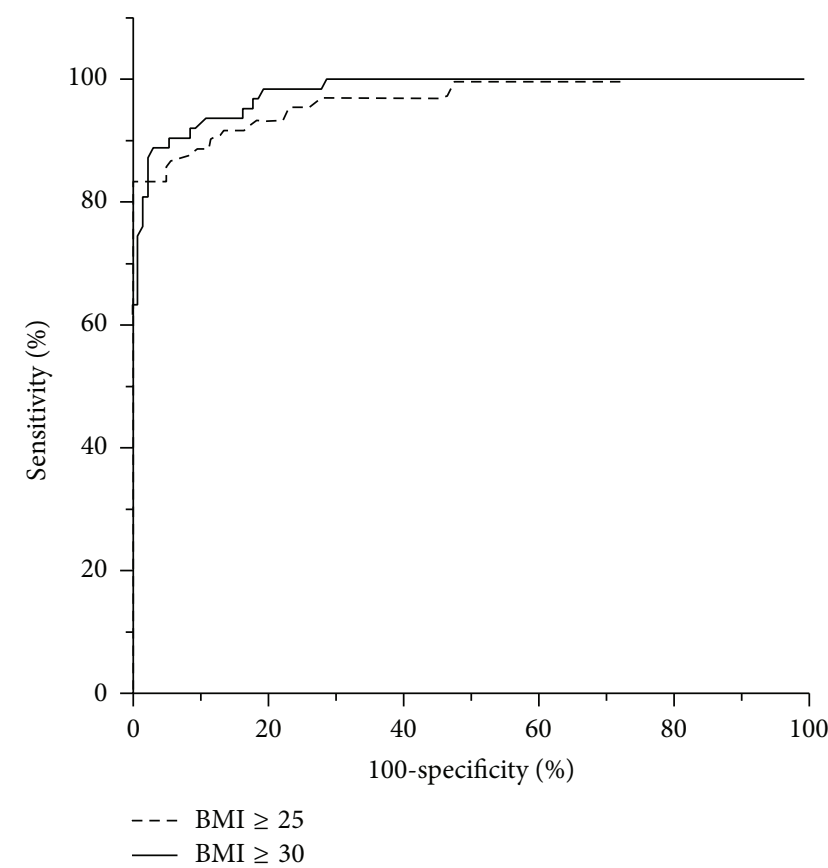

FIGURE 2: ROC curves for the recognition of women with $\mathrm{BMI} \geq 25$ or $\mathrm{BMI} \geq 30$ using the average body circumference (ABC). The area under the $\mathrm{BMI} \geq 25$ curve is 0.97 and that under the $\mathrm{BMI} \geq 30$ curve is 0.98 .

was significantly correlated with body weight as well as with height (Table 3 ).

4.3. Receiver-Operator Characteristic Analysis. In order to test if persons with $\mathrm{BMI} \geq 25$ or with $\mathrm{BMI} \geq 30$ may be recognized using a body circumference, Receiver-Operator Characteristic (ROC) analysis was performed. The results are summarized in Table 4. The best performance in that regard had the ABC. Thus, for ABC, the area under the ROC curve had the value $0.97(0.94-0.99,95 \% \mathrm{CI})$ for the $\mathrm{BMI} \geq 25$ ROC curve and $0.98(0.96-1.0)$ for the BMI $\geq 30$ ROC curve (Figure 2 ). Women with $\mathrm{ABC}>44.0 \mathrm{~cm}$ could be recognized as having $\mathrm{BMI} \geq 25$ with sensitivity $90.2 \%$ and specificity $88.5 \%$. Women with $\mathrm{ABC}>47.1 \mathrm{~cm}$ could be recognized as having $\mathrm{BMI} \geq 30$ with sensitivity $92.2 \%$ and specificity $91.5 \%$ (Table 4).

\section{Discussion}

The purpose of the present work was to evaluate the relationship of various body circumferences with BMI and determine whether any circumference could be used to identify BMIdefined overweight and obese patients as was shown previously for the neck circumference [6].

In the present study, we assessed the relationship between BMI and each of eight individual body circumferences and also between BMI and the average value of several sums of individual circumferences. The correlation between BMI and the averaged sums of individual circumferences was generally stronger than that between BMI and any of the individual 
TABLE 4: ROC analysis for the recognition of women with BMI $\geq 25$ or BMI $\geq 30$ using body circumferences.

(a) Recognition of women with $\mathrm{BMI} \geq 25$. (prevalence of $\mathrm{BMI} \geq 25$ : $68.4 \%$ )

\begin{tabular}{|c|c|c|c|c|}
\hline Body Circumference & Area under the ROC curve & Cutoff value $(\mathrm{cm})$ & Sensitivity (\%) & Specificity (\%) \\
\hline $\mathrm{ABC}$ & $0.97(0.94-0.99)$ & $>44.0$ & 90.2 & 88.5 \\
\hline $\mathrm{UBC}$ & $0.94(0.91-0.94)$ & $>36.7$ & 87.9 & 86.9 \\
\hline LBC & $0.93(0.89-0.96)$ & $>56.3$ & 84.9 & 82.0 \\
\hline$(\mathrm{N}+\mathrm{W}+\mathrm{H}+\mathrm{A}+\mathrm{Th}) / 5$ & $0.96(0.94-0.98)$ & $>58.0$ & 90.2 & 86.9 \\
\hline$(\mathrm{W}+\mathrm{H}+\mathrm{A}+\mathrm{Th}) / 4$ & $0.96(0.93-0.98)$ & $>63.9$ & 90.9 & 85.3 \\
\hline Neck & $0.88(0.83-0.93)$ & $>32.6$ & 87.1 & 75.4 \\
\hline Waist & $0.90(0.86-0.95)$ & $>83.9$ & 90.2 & 73.8 \\
\hline Hip & $0.93(0.89-0.96)$ & $>101.4$ & 90.2 & 80.3 \\
\hline
\end{tabular}

(b) Recognition of women with $\mathrm{BMI} \geq 30$. (prevalence of $\mathrm{BMI} \geq 30$ : $33.2 \%$ )

\begin{tabular}{|c|c|c|c|c|}
\hline Body Circumference & Area under the ROC curve & Cutoff value $(\mathrm{cm})$ & Sensitivity (\%) & Specificity (\%) \\
\hline $\mathrm{ABC}$ & $0.98(0.96-0.99)$ & $>47.1$ & 92.2 & 91.5 \\
\hline UBC & $0.95(0.92-0.98)$ & $>39.2$ & 92.2 & 85.3 \\
\hline LBC & $0.96(0.93-0.99)$ & $>59.5$ & 90.6 & 87.6 \\
\hline$(\mathrm{N}+\mathrm{W}+\mathrm{H}+\mathrm{A}+\mathrm{Th}) / 5$ & $0.98(0.97-1.0)$ & $>62.5$ & 93.8 & 91.5 \\
\hline$(\mathrm{W}+\mathrm{H}+\mathrm{A}+\mathrm{Th}) / 4$ & $0.98(0.97-0.99)$ & $>69.6$ & 93.8 & 91.5 \\
\hline Neck & $0.88(0.83-0.93)$ & $>34.0$ & 87.5 & 73.6 \\
\hline Waist & $0.93(0.89-0.96)$ & $>90.6$ & 92.2 & 76.7 \\
\hline Hip & $0.96(0.94-0.99)$ & $>109.8$ & 90.6 & 89.2 \\
\hline
\end{tabular}

$\mathrm{ABC}$, average body circumference, average of (neck + waist + hip + arm + forearm + wrist + thigh + ankle $)$.

UBC, upper body circumference, average of (neck + waist + arm + forearm + wrist).

LBC, lower body circumference, average of (hip + thigh + ankle).

$\mathrm{N}=$ neck, $\mathrm{W}=$ waist, $\mathrm{H}=$ hip, $\mathrm{A}=\mathrm{arm}$, and $\mathrm{Th}=$ thigh. Area under the ROC curve $(95 \% \mathrm{CI})$. Cutoff value of body circumferences.

body circumferences (Table 2). Thus, in the entire study population, BMI was strongly correlated with the average body circumference $(\mathrm{ABC})$ with regression coefficient $R^{2}=$ 0.89 , which implies that $89 \%$ of the variation of $\mathrm{BMI}$ is due to $\mathrm{ABC}$ (Table 2). In the female participants in our study, we found a strong positive correlation between $\mathrm{BMI}$ and $\mathrm{ABC}$, between $\mathrm{ABC}$ and body weight, and between $\mathrm{BMI}$ and body weight as expected and a significant but weaker correlation between body weight and height. There was not significant correlation between BMI and height or between $\mathrm{ABC}$ and height. These results taken together imply that body weight depends much more on the average body circumference than on height and that the strong relationship of $\mathrm{ABC}$ with $\mathrm{BMI}$ may be explained mainly by the strong relationship between $\mathrm{ABC}$ and body weight.

The measurement of BMI (or of body weight) cannot differentiate adipose from lean body mass. Therefore, in slim-bodied persons (presumably with normal BMI), BMI reflects more the lean body mass than in persons with excess adipose tissue (with high BMI). This is a reason for the poor diagnostic accuracy of BMI to diagnose obesity as measured by other direct methods, especially for persons in the intermediate BMI ranges [7-10]. An upper body fat distribution is considered to have generally a worse prognosis when compared to a lower body fat distribution [11]. It would be therefore of interest to compare the relationship of upper body circumference (UBC) with BMI to that of lower body circumference (LBC). Thus, in the entire study population, simple correlation of BMI with the $\mathrm{UBC}\left(R^{2}=0.83\right)$ and with the LBC $\left(R^{2}=0.79\right)$ showed that $83 \%$ of the variation of BMI is due to the UBC and $79 \%$ is due to the LBC. In contrast, in the overweight women, $48 \%$ of the variation of the BMI may be explained by UBC compared to only $24 \%$ explained by $\mathrm{LBC}$, while, in the obese women, UBC and $\mathrm{LBC}$ explain practically the same percentage of variation $(45 \%$ and $42 \%$ resp.), and the same applies to normal women in whom $29 \%$ of the variation of BMI is explained by UBC and $24 \%$ by LBC (Table 2). Among the three BMI stratified subgroups, only in the overweight a positive correlation was found between waist/hip ratio and BMI. These data imply that women in the intermediate range of BMI tend to accumulate fat preferably in the waist when gaining weight.

ROC analysis showed that ABC can identify BMI-defined overweight or obese women with very good sensitivity and specificity (Table 4, Figure 2). However, in terms of sensitivity and specificity, the performance of some other body circumferences was practically not inferior to that of $\mathrm{ABC}$ (Table 4). Also, UBC and LBC in their ability to identify overweight or obese women were practically not different.

Heymsfield et al. [12] studied the relationship between BMI and five individual circumferences (arm, waist, hip, thigh, and calf) and between BMI and the average of the sum of these five circumferences using analytical methods different from the methods used in the present study. Our findings agree with the results of these authors who found that BMI (represented by body volume/height ratio) was 
strongly correlated with the average as well as with each of the individual circumferences [12]. In our study, we included neck circumference because several studies showed this circumference to be a useful anthropometric measure of obesity $[6,13,14]$. In the present study, we considered also wrist and ankle circumferences representing regions where it is less likely for fat to accumulate in obesity.

The following conclusions may be drawn from the results of our study. In a population of women with a wide range of $\mathrm{BMI}$, the average of the sum of eight body circumferences $(\mathrm{ABC})$ had a very strong correlation with BMI; however, the average of some other more convenient sums of circumferences (as shown in Table 2) had almost equally strong correlations with BMI. The degree of correlation between individual circumferences and BMI was generally smaller than that between averaged sums of circumferences and BMI. Among individual circumferences, the hip and the waist had the strongest and practically not different correlation with BMI. ROC analysis demonstrated that an ABC circumference can identify women with $\mathrm{BMI} \geq 25$ or with $\mathrm{BMI} \geq 30$ with very good sensitivity and specificity. Measurement of body circumferences is simple, does not need special equipment for the measurement of body weight and height, and therefore may be especially suitable for field epidemiological studies. The time required for the measurement of the eight body circumferences was approximately one minute comparing favorably with the time required for the measurement of weight and height. It should be noted that an accurate measurement of height may be a time-consuming procedure. Average body circumference can be a surrogate of BMI.

\section{Abbreviations}

BMI: $\quad$ Body mass index

ABC: $\quad$ Average body circumference, average of (neck + waist + hip + arm + forearm + wrist + thigh + ankle)

UBC: $\quad$ Upper body circumference, average of (neck + waist + arm + forearm + wrist)

LBC: $\quad$ Lower body circumference, average of (hip + thigh + ankle)

ROC analysis : Receiver-operator characteristic analysis.

\section{Conflict of Interests}

No conflict of interests is declared by the authors.

\section{References}

[1] A. Keys, F. Fidanza, M. J. Karvonen, N. Kimura, and H. L. Taylor, "Indices of relative weight and obesity," Journal of Chronic Diseases, vol. 25, no. 6-7, pp. 329-343, 1972.

[2] D. P. Guh, W. Zhang, N. Bansback, Z. Amarsi, C. L. Birmingham, and A. H. Anis, "The incidence of co-morbidities related to obesity and overweight: a systematic review and meta-analysis," BMC Public Health, vol. 9, article 88, 2009.

[3] J. C. Seidell, H. S. Kahn, D. F. Williamson, L. Lissner, and R. Valdez, "Report from a centers for disease control and prevention workshop on use of adult anthropometry for public health and primary health care," The American Journal of Clinical Nutrition, vol. 73, no. 1, pp. 123-126, 2001.

[4] M.-A. Cornier, J.-P. Després, N. Davis et al., "Assessing adiposity: a scientific statement from the American Heart Association," Circulation, vol. 124, no. 18, pp. 1996-2019, 2011.

[5] V. A. Moyer, "Screening for and management of obesity in adults: U.S. preventive services task force recommendation statement," Annals of Internal Medicine, vol. 157, no. 5, pp. 373378, 2012.

[6] L. Ben-Noun, E. Sohar, and A. Laor, "Neck circumference as a simple screening measure for identifying overweight and obese patients," Obesity Research, vol. 9, no. 8, pp. 470-477, 2001.

[7] L. S. Piers, M. J. Soares, S. L. Frandsen, and K. O'dea, "Indirect estimates of body composition are useful for groups but unreliable in individuals," International Journal of Obesity and Related Metabolic Disorders, vol. 24, no. 9, pp. 1145-1152, 2000.

[8] D. C. Frankenfield, W. A. Rowe, R. N. Cooney, J. S. Smith, and D. Becker, "Limits of body mass index to detect obesity and predict body composition," Nutrition, vol. 17, no. 1, pp. 26-30, 2001.

[9] A. Romero-Corral, V. K. Somers, J. Sierra-Johnson et al., "Accuracy of body mass index in diagnosing obesity in the adult general population," International Journal of Obesity, vol. 32, no. 6, pp. 959-966, 2008.

[10] D. O. Okorodudu, M. F. Jumean, V. M. Montori et al., "Diagnostic performance of body mass index to identify obesity as defined by body adiposity: a systematic review and metaanalysis," International Journal of Obesity, vol. 34, no. 5, pp. 791799, 2010.

[11] M. D. Jensen, "Role of body fat distribution and the metabolic complications of obesity," The Journal of Clinical Endocrinology and Metabolism, vol. 93, pp. S57-S63, 2008.

[12] S. B. Heymsfield, A. Martin-Nguyen, T. M. Fong, D. Gallagher, and A. Pietrobelli, "Body circumferences: clinical implications emerging from a new geometric model," Nutrition and Metabolism, vol. 5, no. 1, article 24, 2008.

[13] D.-H. Lou, F.-Z. Yin, R. Wang, C.-M. Ma, X.-L. Liu, and Q. $\mathrm{Lu}$, "Neck circumference is an accurate and simple index for evaluating overweight and obesity in Han children," Annals of Human Biology, vol. 39, no. 2, pp. 161-165, 2012.

[14] J. Aswathappa, S. Garg, K. Kutty, and V. Shankar, "Neck circumference as an anthropometric measure of obesity in diabetics," North American Journal of Medical Sciences, vol. 5, no. 1, pp. 28-31, 2013. 


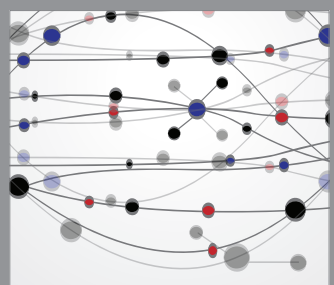

The Scientific World Journal
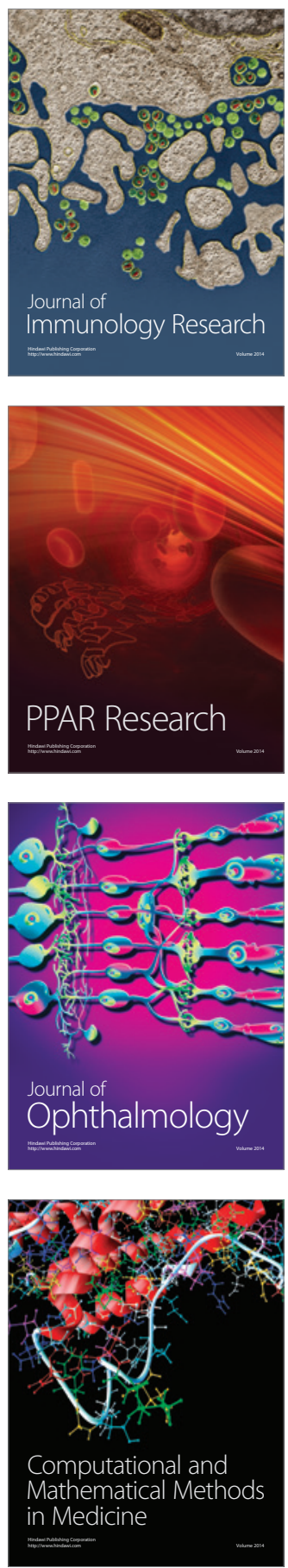

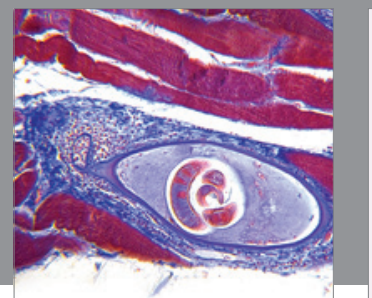

Gastroenterology

Research and Practice
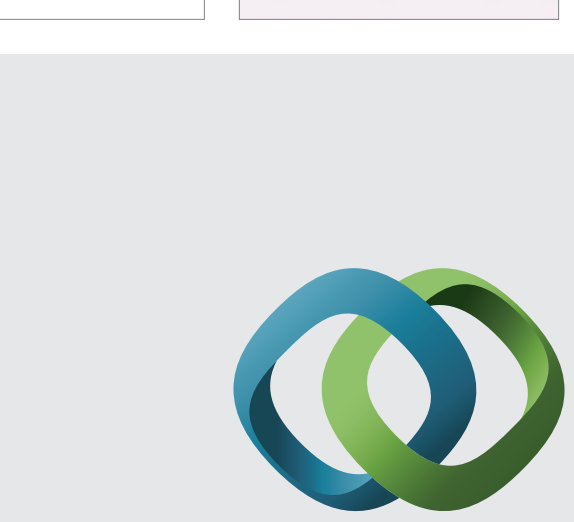

\section{Hindawi}

Submit your manuscripts at

http://www.hindawi.com
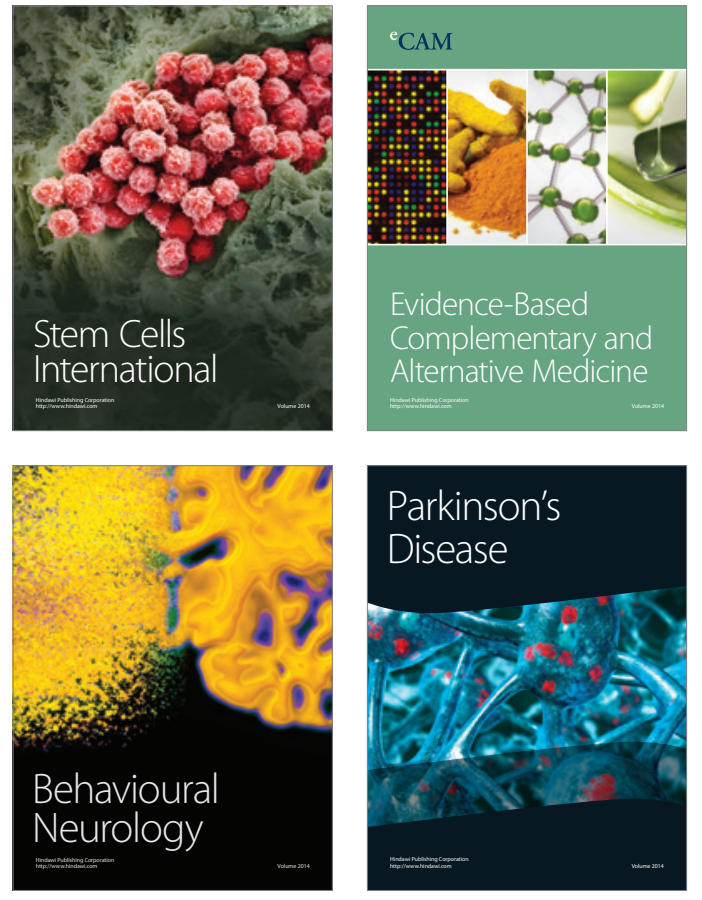
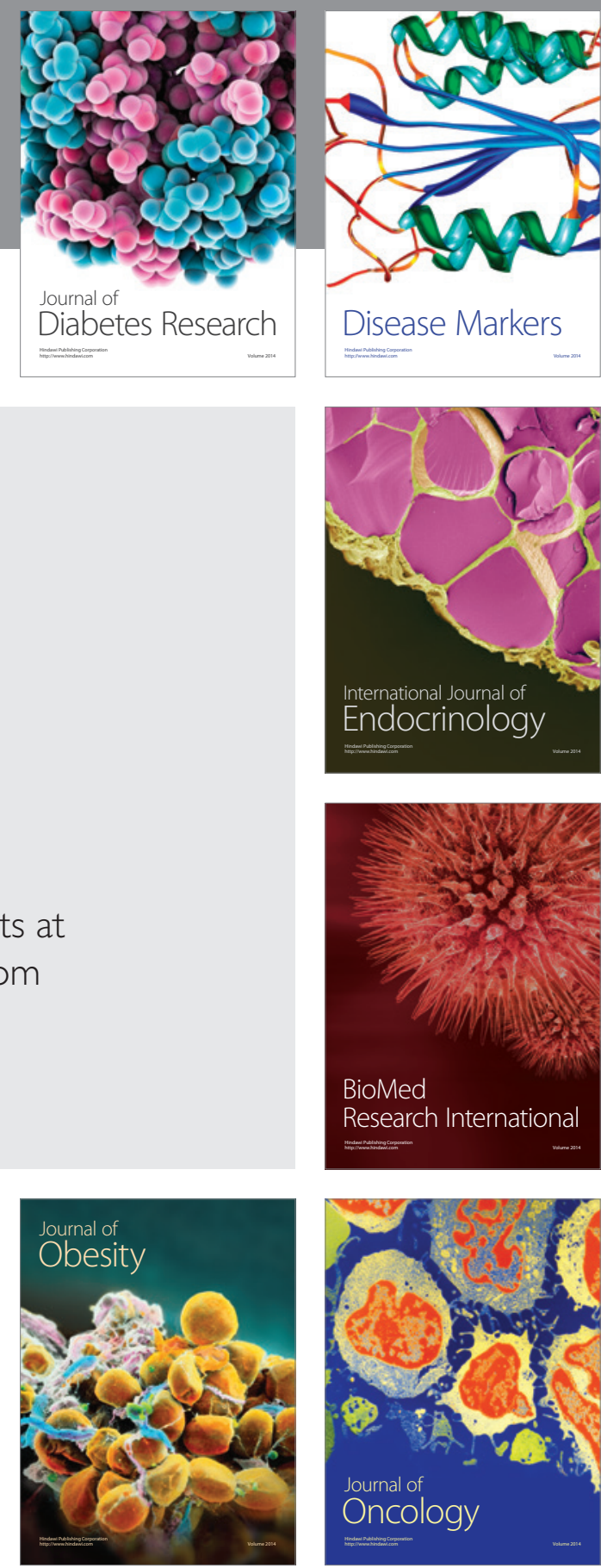

Disease Markers
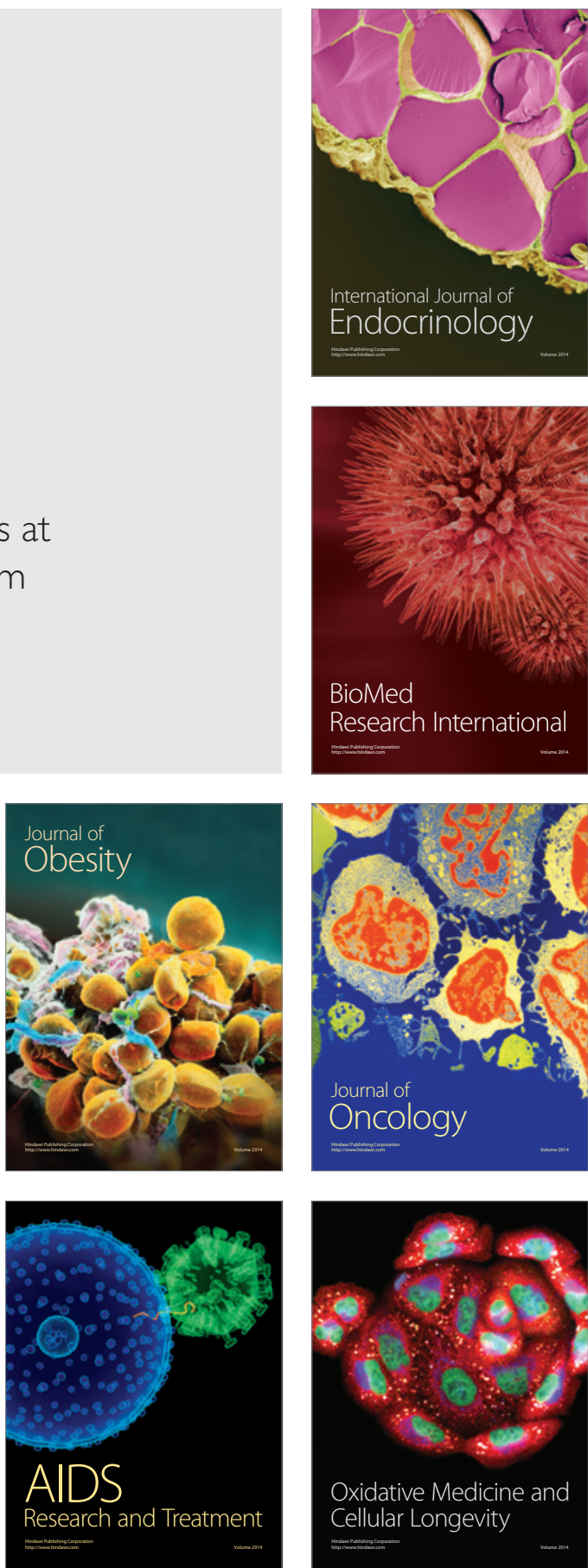